\section{ECOLOGISMO, IGUALDAD Y}

RESPONSABILIDAD CIVIL

Una Visión de la $\mathrm{Pu}-$

\section{blicidad Social Tele-}

visiva

\section{Alfonso Cortés González}

Doctor

Departamento de Comunicación Audiovisual y Publicidad. Universidad de Málaga.

Email: acealfonsocortes.com

\section{José Patricio Pérez Rufí}

Doctor en Comunicación Audiovisual

Departamento de Comunicación Audiovisual y Publicidad. Universidad de Málaga.

Email: patricioperez@uma.es

\section{Resumen}

La publicidad social y el marketing de causas están de moda. En el presente artículo, a partir del análisis de una serie de campañas catalogadas como sociales, se propone un debate conceptual vital, y se argumenta, creemos que fundamentadamente, que este tipo concreto de publicidad que se estudia, debe entenderse y plantearse de manera

\section{Palabras clave}

Publicidad social, televisión, cambio social, comunicación social

Key Words

Social Advertising, television, Social

Change, Social Communication

\section{Abstract}

Social Advertising and Commitment Marketing are in fashion. This paper is

made from the analysis of a group of

campaigns labelled as Socials, it is proposed a vital conceptual debate, and so we argue that this kind of advertising we study, must be understood in a different

way, in order to not confound the advertising that uses social argument from

other types of communication for the Social Change. 
distinta, para no confundir publicidad con argumento social con la comunicación para el cambio social.

\section{Introducción}

La primera idea que asociamos intuitivamente al concepto de publicidad social, es la de un tipo de comunicación publicitaria que ponen en marcha ONGs, Instituciones Públicas y "obras sociales" de las cajas de ahorro. Sin embargo, en este tiempo de marketing de causas, las empresas aprovechan estos discursos, aparentemente vinculados con el cambio social, para insertarlos en sus políticas comunicativas en general.

La publicidad social debe ser analizada, a nuestro entender, como un género dentro de la comunicación publicitaria, en lugar de una forma o modalidad con entidad propia, siempre y cuando, estemos hablando realmente de comunicación comercial que busca el lucro o beneficio en cualquier sentido del propio emisor. Sería conveniente, por tanto, diferenciar publicidad social frente a publicidad para el cambio o la transformación social. Hoy día, cada vez es más común observar cómo las estrategias publicitarias de distintas organizaciones (ya sean instituciones o empresas comerciales y privadas) apelan a su compromiso moral y ético con la sociedad, y esto revierte en una mejora en la imagen de marca, y no necesariamente (en muchos casos de ninguna manera) en mejorar la sociedad y sus relaciones en su conjunto.
La primera parte del título (ecologismo, igualdad y responsabilidad civil) responde a los tres temas de referencia, a nivel discursivo, en la llamada (podemos discutir si es mal llamada) publicidad social. Asuntos como el cambio climático, la pertinencia de reciclar productos, y el compromiso con la igualdad de género, por poner tres ejemplos, han pasado a ser en los últimos años en nuestro país, grandes preocupaciones que los ciudadanos tienen asimiladas en su mente $^{1}$, o al menos así parece tras revisar la agenda mediática. En un texto sobre publicidad social, la profesora Rocío Chamizo de la Universidad Málaga explica que:

\footnotetext{
${ }^{1}$ Podemos revisar un 'pulsómetro' reciente de la SER en
}

[http://www.cadenaser.com/static/pulsometro/anteriores /encuesta_071029.html] consultada el 6 de noviembre de 2007. Sea o no así, el medio ambiente, la desigualdad social y la pobreza aparecen dentro de los 30 problemas más importantes, según los sondeos de opinión que se hacen en nuestro país. La cuestión es que tenemos que atender cómo se hace la encuesta, y por qué en un momento determinado las personas responden cuáles son, a su entender, los principales problemas del país. Esta idea que apuntamos aquí nos remite entre otras referencias, a la espiral del silencio de Noelle-Neuman, a los trabajos de la psicología social de la comunicación sobre opinión pública, y al modelaje a la hora de elaborar (o cocinar) encuestas. 
A través de la reconocida influencia de los medios de comunicación, se pretende que el ciudadano como sujeto social conozca y esté informado de los asuntos sociales, realice una reflexión crítica en torno al tema y su postura ante el mismo y actúe en consecuencia (Chamizo, 2006)

No obstante creemos que esta afirmación debe ser matizada y profundizada. Bien es cierto que los medios de comunicación ejercen una influencia importante en la sociedad, y por tanto, es una herramienta susceptible de ser usada en la educación y en el cambio social, para mejorar nuestra sociedad. Sin embargo, que pueda hacerlo, no significa, concretando el tema, que toda la publicidad con contenido social eduque, sensibilice o informe en esta dirección. Es más, una cuestión de fondo es preguntarnos si realmente la publicidad puede ser útil para estos cometidos. Ahora bien, como veremos en el punto en el que analizamos las campañas, tomando el planteamiento de Chamizo cuando dice que la comunicación social "pretende que el ciudadano conozca y esté informado de asuntos sociales" no se cumple en casi ninguna de las campañas sociales de empresas, ya que estos discursos no revelan nada que los receptores (ciudadanos) no supieran o no estuviesen previamente sensibilizados. El juego, por tanto, está en aprovecharse de un tema sensible, para sacar una ventaja en términos comerciales o de imagen de marca. Es decir si hay posibilidad, hay negocio.
Todo lo que preocupa a las personas, es susceptible de ser empleado en distintas estrategias de comunicación; al generar incertidumbre y desasosiego tiene mayor capacidad para captar la atención de los distintos públicos. Así vemos los temas recurrentes en la publicidad, son asuntos con los que las personas de manera social o fisiológica se siente comprometida (es decir ante los temas que más nos llegan a nuestra sensibilidad, sea innata o construida por distintos agentes sociales): sexo, violencia, marginación, drogas, velocidad, ecologismo, malos tratos, etc. En cualquier caso, más adelante, desarrollaremos más ampliamente lo que aquí planteamos.

Aclaramos, como indicamos al comienzo del texto, que cuando hablamos de publicidad social no nos referimos a la publicidad para el cambio social, que sería aquella realmente educativa ya que, en palabras de Mario Kaplún "Cuando hacemos comunicación educativa, estamos siempre buscando, de una u otra manera, un resultado formativo. Decimos que producimos nuestros mensajes como instrumentos para una educación popular como alimentadores de un proceso educativo transformador" (Kaplún, 1998). En este texto nos acercamos, sin embargo, a un tipo publicidad que en realidad es comercial, pero que tiene un argumento social a modo de caparazón, que en numerosos casos es confundida con la publicidad comprometida con la trasformación social, por compartir discursos 
similares, aunque persigan distintos objetivos.

Por lo tanto, en este texto aportamos una visión de la publicidad llamada social ${ }^{2}$, pero aquella que no pretende como fin último el cambio social, sino revertir en beneficios propios y empresariales, empleando argumentos vinculados con la solidaridad o el medio ambiente, en lugar del precio o las características técnicas del producto, como una ventaja competitiva en términos publicitarios, es decir, se usa estas causas justas para diferenciarse de la competencia en términos de mercado. A fin de cuentas, esta publicidad social es en realidad publicidad comercial. En este sentido, aquí defendemos, tras el análisis de distintas piezas, que esta publicidad no tiene en realidad características suficientes y propias como para ser un tipo específico de comunicación, y que debería por tanto entenderse, si acaso, como un género dentro de la propia publicidad comercial. Esta cuestión se argumentará a lo largo del texto.

\footnotetext{
${ }^{2}$ Término que acatamos, y que por tanto estamos buscando otro para la publicidad que sí entendemos realmente como social
} 


\section{Objetivos}

El primer objetivo de esta investigación, que hemos abordado de forma previa al establecimiento de objetivos más específicos, será determinar una definición o un criterio que nos permita distinguir entre publicidad social y publicidad para el cambio social: aunque ambas puedan tomar como motivos temáticas que preocupan socialmente, es en último término en su finalidad, como veremos, donde encontramos divergencias entre ambas prácticas de comunicación.

El objetivo principal de nuestro análisis será demostrar que el tipo de publicidad televisiva objeto de este estudio hace prevalecer los valores de la marca (o del producto) por encima del fin educativo que aparentemente cabría suponerles. De esta forma, intentaremos observar la efectividad de dicha campañas atendiendo a sus objetivos y evaluando el contenido del discurso; preten- demos así apuntar al beneficiario último de tales prácticas comunicativas.

Nos cuestionaremos igualmente por los motivos que originan dicha comunicación por parte de las empresas e instituciones: ¿responden a una tendencia de adaptación del discurso publicitario a cuestiones que capten actualmente la atención del consumidor, o existe un verdadero deseo de contribuir a sensibilizar a la sociedad sobre cuestiones ante las que se procura un cambio de actitudes y comportamientos por el bien público? Nos preguntaremos en último término por el sentido de campañas que, habida cuenta del alto coste económico que supone la inversión en televisión, cabría suponerles un objetivo desinteresado desde el punto de vista comercial, como parte de una solidaridad que ¿cabría exigir a empresas e instituciones?

\section{Metodología}

Para alcanzar nuestros objetivos de partida, así como poder obtener la verificación de nuestra argumentación, es preciso plantear un análisis de la publicidad y sus objetivos estratégicos finales para delimitar los conceptos y establecer los nexos de unión entre ambas cuestiones. Se ha llevado a cabo el modelo clásico de metodología hipotético-deductiva, lo que significa que partiendo de unas ideas pre-existentes, se contrastan las mismas con los datos empíricos derivados del estudio de investigación. 
Las técnicas de investigación son fundamentalmente el análisis de fuentes documentales, (bibliografía, hemerografía, monografías, declaraciones oficiales, legislación, etc.), y el análisis de contenido de las campañas objeto de nuestro estudio.

\section{Conceptualización y breve discussion sobre la publicidad social}

Elaborar campañas publicitarias, o plantear estrategias comunicativas, siempre ha estado vinculado a cualquier tipo de aspiración humana, desde la guerra hasta la reivindicación de carácter social. Sin embargo buenas estrategias y campañas, de gran eficacia, se han ejecutado principalmente de manera más o menos coherente, por parte de los órganos de poder en la inmensa mayoría de los casos. Hoy día, con el acceso cada vez más amplio a las nuevas tecnologías y el abaratamiento de los costes de producción de la comunicación, grupos sociales que anteriormente no tenían capacidad de comunicar a determinadas audiencias, hoy día, con esfuerzo e imaginación, pueden hacerse un hueco en el aparentemente férreo y hermético discurso mediático global y "oficial". No obstante, hace falta mucha más formación específica para que pequeñas asociaciones y colectivos puedan maximizar sus esfuerzos en materia de comunicación, y concretamente en asuntos publicitarios. Hay que tener claro que hoy día publicidad no es sólo la cuña o el spot, sino que hay muchas más posibilidades, aunque se sigue practicando, en las campañas sociales de la Administración sobre todo, un modelo publicitario que aunque no obsoleto, si es conveniente reformular. Ahora bien, en el presente texto, como declaramos en la introducción, vamos a centrarnos en la "publicidad social" que desarrollan empresas comerciales bajo el paraguas de su propia imagen de marca.

La publicidad social tiene "como objetivos finales, que el destinatario acepte, modifique o abandone ciertas ideas y/o conductas" (Chamizo, 2006). Pero claro, ¿de qué tipo de ideas y/o conductas estamos hablando? Podemos modificar una conducta de no-consumo, hacia otra de consumo, o podemos cambiar una conducta violenta hacia otra no-violenta. La paradoja reside en que existen campañas con discursos sociales, críticos y aparentemente conducentes a mejorar nuestras conductas sociales, pero que están orientados realmente a atraer buenos resultados para la organización que invierte en estas campañas. Esta afirmación se contrastará en el punto en el 
que analizamos una serie de campañas de este tipo.

Profundizando en este panorama conceptual y para entender mejor el significado real de publicidad social es vital tomar como referencia a Maricruz Alvarado, para quien "La finalidad en la transmisión de ideas por parte de la publicidad no tiene por qué ser sólo favorable al emisor, sino que puede serlo para los receptores mismos, para el conjunto de la sociedad" (Alvarado, 2003). Estimamos pertinente matizar estas palabras y sustituir que este tipo de publicidad "puede ser favorable al receptor" por "tienen que ser favorable al receptor", y por extensión a la sociedad en su conjunto, debido a que el modelo social, se fundamenta de manera muy importante en el tipo y calidad de las relaciones que establecen sus individuos. La cita recogida al comienzo del párrafo, pretende desarrollar el concepto de publicidad social, que es un tipo de publicidad con finalidad y contenido cívico. De este modo, y tomando esta postura de Alvarado, una publicidad social, debería ser aquella con finalidad y contenidos orientados a la incitación del cambio social, que ha de ser continuo y progresivo.

Esto nos lleva a entender que los contenidos y formas de la publicidad social son muy heterogéneos y que en un primer momento es difícil de delimitar conceptualmente, y saber concretamente qué es y qué no es publicidad social. Siguiendo por tanto estos argumentos, podemos empezar a afirmar que lo que en este texto empeza- mos llamando publicidad social, no cumple los requisitos para denominarse como tal.

Por esta cuestión compleja en cuanto al cuño terminológico, no resulta fácil asimilar el concepto de publicidad social en un primer momento, estando tan extendido en el ámbito profesional una concepción de la publicidad social simplemente teniendo en cuenta la temática y obviando la finalidad. Esto es por dos motivos: En primer lugar el volumen de publicidad social (real, es decir para el cambio social) respecto a comercial es insignificante, y en segundo lugar por que incluso es obviada en la propia Ley General de Publicidad, y por si fuera poco, existen asignaturas de Teoría de la Publicidad en diversos centros de formación que ni siquiera la nombran. Por ello, vamos brevemente a definir de modo más concreto qué es la publicidad social, asumiendo que los lectores están formados en comunicación y en consecuencia no necesitamos un repaso teórico, a modo enciclopédico, sobre el término publicidad.

En otras ocasiones ya nos referimos a Feliu cuando nos comenta a partir de Moliner Tena (Moliner, 1998) que la publicidad social, conceptualmente, deriva del marketing social, que "es una extensión del marketing que estudia la relación de intercambio que se origina cuando el producto es una idea o causa social" (Felíu, 2004), y de este modo se estima que la publicidad es una herramienta del marketing más, y se lanza la pregunta de por qué no se reconoce 
formalmente al adjetivo social a la publicidad como se hace con el marketing.

La cuestión, en nuestra opinión no es tan simple. El termino marketing está estrechamente vinculado con el mercado (su traducción vendría a ser como mercadotecnia), y la publicidad que, por ejemplo, trata de fomentar valores o educar (se trata de un tipo específico de publicidad, aunque toda la publicidad en su conjunto es un producto cultural que ayuda a fomentar cosmovisiones), persigue objetivos fuera del mercado. En este caso, la publicidad no podría ser considerada una herramienta del marketing, y sí quizás una herramienta pedagógica. Si existe realmente una publicidad social, esta debería estar en el ámbito de la pedagogía y la sociología, por encima de sus vinculaciones marketinianas. Por ello, y sin querer entrar en debates meramente terminológicos, proponemos que podría resultar útil buscar un nuevo término para denominar este tipo de publicidad. Sin embargo, para no extendernos esta discusión vamos a continuar aclarando el concepto de este tipo de publicidad.

La tradición de estudiar la publicidad dentro del ámbito del marketing está consolidada en la literatura sobre estos temas. Desde esta perspectiva académica siempre se nos plantean definiciones aparentemente asépticas $^{3}$, y en esta línea Kotler y Roberto

\footnotetext{
${ }^{3}$ Decimos aparentemente sin carga peyorativa puesto que lo aséptico es difícil de encontrarlo en el ámbito de las Ciencias Sociales.
}

(que mencionana explícitamente el 'cambio social') nos proponen una de marketing social que se podría asimilar al tipo de publicidad que estamos abordando si se le añade que estamos hablando de prácticas publicitarias: [añadiendo y haciendo constar que hablamos de publicidad, sería]

“... una tecnología del cambio social que incluye el diseño, la puesta en práctica y el control de programas orientados a aumentar la aceptabilidad de una idea o práctica social en uno o más grupos de adoptantes objetivo" (Kotler y Roberto, 1998:29).

Dicho de otro modo, pero diciendo lo mismo, nos encontraríamos con una práctica publicitaria (o de marketing atendiendo al objeto de estudio de Kotler y Roberto) cuyo objetivo sería el cambio social, y sus estrategias estarían orientadas a aumentar la aceptabilidad de los valores y mensajes que se proponen, siempre pensadas estas acciones, como cualquier acción publicitaria, hacia un publico definido y concreto, denominado en nuestra jerga como público objetivo. Es decir, incluso atendiendo a estos autores, no hablaríamos de marketing social (y por tanto mucho menos de publicidad social) si no existe esa motivación por el cambio social, y la acción, a pesar de un discurso y apariencia revolucionaria, simplemente persigue algún tipo de lucro corporativo. Lo veremos de manera más clara en el análisis de las campañas.

A partir de aquí, a pesar de tergiversarse su concepto en muchos casos, se tiene más claro el concepto de este tipo de publici- 
dad. Sin embargo, es necesario vislumbrar qué vinculaciones puede tener 'lo social' en todo esto. Lo social se puede integrar en la publicidad de tres formas distintas, siendo utilizado el mismo término para tres realidades peculiares (por eso discutimos la denominación de publicidad social, que reduce en un solo concepto diferentes modalidades comunicativas). Estos tres ámbitos se pueden establecer según Feliu en:

- 'Lo social' de la publicidad (función social de la publicidad)

- 'Lo social' en la publicidad (publicidad con causa)

- La publicidad de 'lo social' (publicidad social)

Ciertamente, resulta imprescindible para el estudio de este fenómeno estas tres formas de lo social en la publicidad, y hay que tenerlas en cuenta. Sin embargo, en este artículo nos vamos a centrar de manera específica en la publicidad de lo social, es decir en las campañas que emplean el argumento y discurso social como un elemento que potencia sus estrategias de marketing e imagen.

Por lo tanto, aunque a primera vista así lo parezca, este tipo de publicidad no es aquella que tiene por objeto "promover una correcta comunicación social y sensibilizar la conciencia de los ciudadanos en sus pro- blemas morales, civiles y educativos con la ayuda de las herramientas publicitarias profesionales" ${ }^{\text {. }}$. Por lo tanto, estas campañas publicitarias no tratarán en realidad de “poner las herramientas de la publicidad al servicio de temas de utilidad pública alejados de cualquier interés mercantil, sentando las bases de una modalidad de publicidad no comercial, como lo son la publicidad política o la publicidad institucional” (Felíu, 2004), si no que pretenden dinamizar sus sinergias empresariales. Así pues, es un agumento que se nos suma para no considerar estas campañas dentro de las acciones de la publicidad social. Si lo hacemos, a la publicidad social de verdad deberíamos llamarla de otra forma.

La mayor parte de las campañas de este tipo que somos capaces de evocar a priori se difunden a través de la televisión. Este es un medio donde la gente va a entretenerse y evadirse, y el que hoy por hoy ostenta una mayor capacidad de penetración social (sobre todo en la población que va de los 25 años en adelante). Por lo tanto, a continuación vamos a comentar y analizar algunas campañas denominadas sociales que se han difundido en televisión, y contrastaremos y pretenderemos validar la postura planteada en este artículo.

\footnotetext{
${ }^{4}$ Definición propuesta la asociación italiana "Pubblicitá Progresso" [http://www.pubblicitaprogresso.it] consultada el 14 de octubre de 2007.
} 


\section{Análisis de campañas}

Vamos a analizar cuatro piezas publicitarias que son catalogadas como publicidad social, y que son desarrolladas por empresas comerciales. La muestra se hace atendiendo a los tres criterios marco del título. Hemos escogido una pieza de Audi, el conocido fabricante de automóviles, vinculada con la responsabilidad social y civil en la publicidad; un spot de la serie "12 meses 12 causas" de la emisora de televisión Telecinco, como ejemplo del compromiso con la salud; una controvertida pieza gráfica de Puntomatic (detergente) que se declara luchadora por la igualdad de género, y por último una pieza publicitaria audiovisual de la campaña de "energía verde" de Iberdrola, con un discurso decididamente ecologista. Comenzaremos en el orden aquí propuesto.

\section{1. "Señales", campaña vinculada a la RSC de Audi}

El spot publicitario llamado "Señales" de Audi, es un claro ejemplo de las campañas vinculadas a la $\mathrm{RSC}^{5}$ de las empresas. Presenta un discurso humano, cercano, responsable y con la puesta en escena de perseguir el cambio social. Este spot se enmarca concretamente dentro de la iniciativa

\footnotetext{
${ }^{5}$ Siglas de Responsabilidad Social Corporativa
}

"Attitudes"6 auspiciada por esta marca de automóviles. La campaña es agradable, y en primer momento conmueve, y nos da una imagen irreprochable de Audi. Pero si nos revolvemos un poco en la silla y nos paramos a pensar, tras leer el cierre ("iniciativa social de Audi, promoción de la educación vial, y protección del medio ambiente”), nos preguntaremos seguramente cómo es posible que con esta campaña se promocione la educación vial, y más allá de eso, cómo protege Audi con esta campaña el medio ambiente. Realmente no tiene nada que ver. La cuestión es que en este universo audiovisual y falaz, lo importante, podemos preguntarnos, no es hacer las cosas, sino parecer o decir que se hacen, y eso la publicidad (al igual que cualquier tipo de comunicación social ${ }^{7}$ ) lo tiene bien asimilado desde hace tiempo.

\footnotetext{
${ }^{6}$ [http://www.attitudes.org] consultada el 1 de octubre de 2007

${ }^{7}$ Todo tipo de comunicación tiene irremediablemente un planteamiento estratégico, y por tanto la gestión de la información y del discurso están orientados siempre hacia la consecución de unos objetivos.
} 


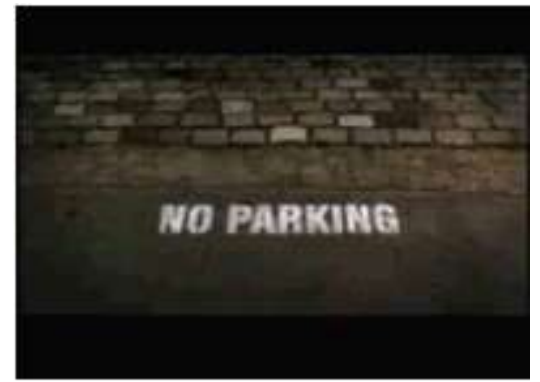

Fig. 1 No aparcar

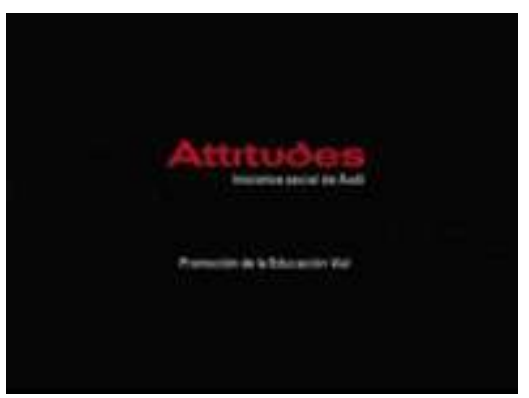

Fig. 3 Prohibido fumar

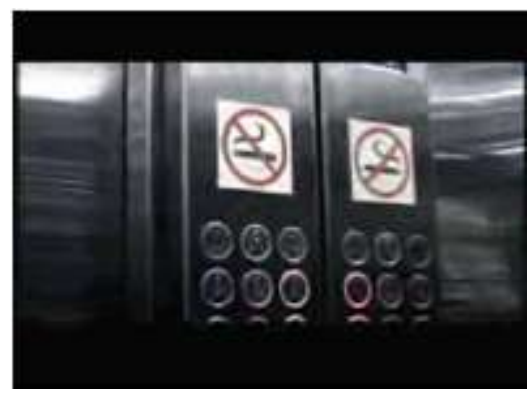

Fig. 5 Attitudes. Iniciativa social de Audi.

Promoción de la educación vial, protección del medio ambiente

En principio y atendiendo a la postura de la empresa anunciadora, este spot no se utilizó para vender coches, sino que forma parte

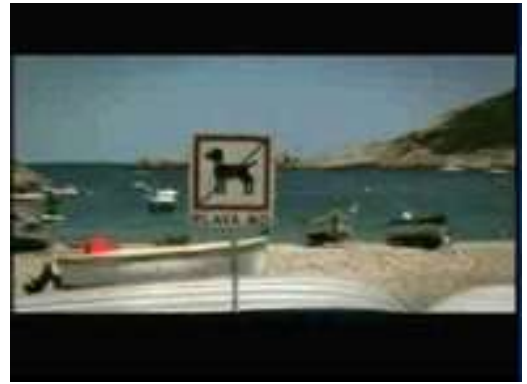

Fig. 2 Prohibido perros en la playa

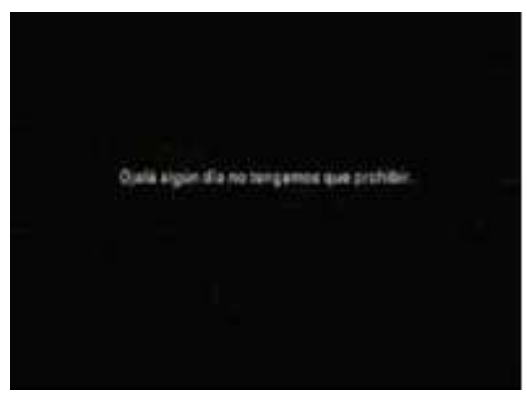

Fig. 4 Ojalá algún día no tengamos que prohibir

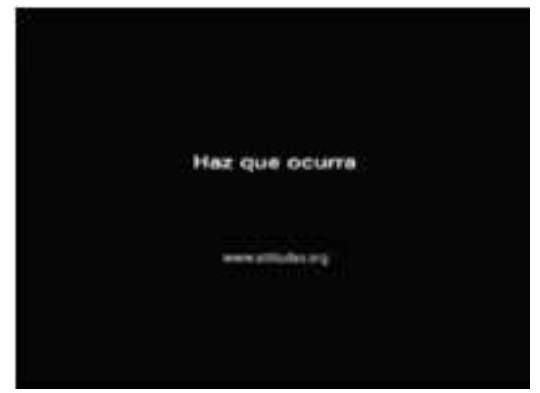

Fig. 6 Haz que ocurra www.attitudes.org

de un plan más ambicioso, que como mencionamos más arriba se denomina Attitu- 
des. Este proyecto según declara la propia compañía alemana:

Es la iniciativa social de Audi creada en 1999 para expresar su compromiso con la protección del medio ambiente y la promoción de la educación vial.

Sus proyectos, así como sus campañas de concienciación, se distinguen por su tono fresco y diferente, buscando siempre fomentar una actitud positiva y socialmente responsable.

Descúbrelos aquí, junto con las noticias más recientes y comparte tus opiniones. Nos gusta conocer otros puntos de vista ${ }^{8}$.

Entendiendo lo que se plantea en este artículo, resulta muy pertinente formular dos preguntas, siendo la primera ¿qué persigue Audi con estas campañas? y la segunda sería ¿Por qué la hace en nombre de Audi? A la primera pregunta se le puede dar tres posibles respuestas: a. 'Audi persigue mejorar su imagen y así repercutir en ventas más sólidas', o b. 'Audi busca y está comprometida con un mundo mejor', y c. Audi quiere invertir en ella misma y además mejorar la sociedad'. Responder a la segunda pregunta nos resulta mucho más sencillo: Audi lanza estas campañas en su nombre para beneficiar la propia imagen corporativa (en cualquier caso) con estos anuncios. Este es el quid de la cuestión, en el debate conceptual

8 [http://www.audi.es/audi/es/es2/attitudes.html] Consultada el 1 de octubre de 2007 sobre qué es publicidad social que planteamos al comienzo del presente artículo. Dado que el spot tiene vocación de beneficiar, y beneficia a la empresa comercial que la auspicia, no creo que sea conveniente catalogar estas campañas, obviamente legítimas, como sociales (entendida para el cambio social, que debido al reiterado uso del término "publicidad social" hay que matizar), porque como se expuso al principio del texto, las campañas real y conceptualmente sociales son altruistas y buscan el beneficio del receptor, de la sociedad, y no del emisor, aunque se pueda argumentar que este tipo de anuncios se beneficia tanto emisor como receptor; pero insistimos que esa no es la filosofía de esta forma de publicidad. Por tanto, se denominaría esta campaña de Audi (como a todas las de esta naturaleza) simplemente campañas comerciales, ya sea empleando un discurso y argumento social, o bien lanzándonos los típicos reclamos sobre precio, facilidades de pago, o características técnicas, para fortalecer la capacidad de venta y cuota de mercado de las empresas en cuestión. Como vemos es la misma cosa, y si no lo es, podríamos crear tantos tipos específicos de publicidad como géneros, argumentos y temáticas publicitarias existan.

\section{2. "12 meses, 12 cau- sas", campaña social de} Telecinco

En diciembre de 1999 se inicia esta iniciativa "solidaria de Telecinco por el que la 
cadena se comprometía a dedicar cada mes parte de sus contenidos y recursos a informar acerca de una causa social diferente a lo largo del año"”. Telecinco en 2004 convocó sus primeros Premios 12 meses 12 causas, y en 2005 creó la fundación del mismo nombre, para gestionar todas las posibles actividades de RSC de la emisora, que realmente se resumen en dos: la campaña publicitaria por todos conocida y los premios anuales. Entendemos, por tanto, que en realidad esta iniciativa, a pesar de su innegable esfuerzo y loables objetivos, se queda en la superficialidad de la comunicación y no trabaja por la solución efectiva de los problemas a los que se hace mención, cuestión que supondría mayores costes, pero que contribuiría a reforzar el compromiso que con esta campaña de comunicación e imagen manifiesta la cadena.

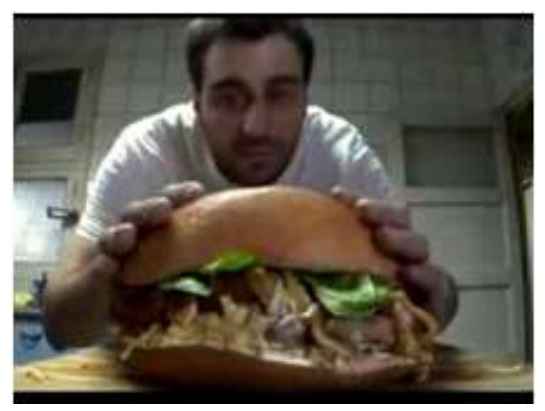

Fig. 7 Campaña 12 meses, 12 causas

${ }^{9}$ Web corporativa de la iniciativa 12 mese, 12 causas: [http://www.12meses12causas.telecinco.es/dn_5.htm] consultada el 28 de noviembre de 2007
Hablamos en concreto, y por poner un ejemplo, del spot cuya causa es "por una alimentación sana” tal como declara el propio eslogan. En este caso, ocurre prácticamente lo mismo que en la campaña que analizamos anteriormente de Audi: la acción se queda en la superficialidad de la comunicación, y obviamente repercute directamente en una mejora de la imagen corporativa de la emisora televisiva. $\mathrm{Si}$ realmente esta causa dispone del firme compromiso de la empresa que la auspicia, se le debería exigir acciones coherentes como inversiones en educación dietética y culinaria, o simplemente programar seriamente contenidos en este sentido ${ }^{10}$. También podríamos abrir un debate sobre cómo una cadena comprometida con la alimentación sana, promociona al mismo tiempo, y acepta publicidad que fomentan hábitos

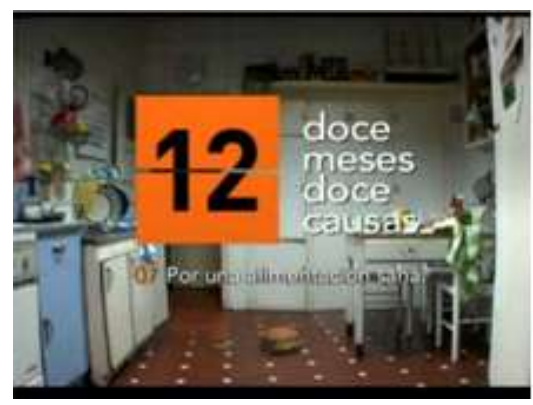

Fig. 8 Campaña 12 meses, 12 causas

${ }^{10}$ ya que la influencia social y la credibilidad, por ejemplo de una noticia, un documental o un programa sobre salud, es bastante mayor que la credibilidad e capacidad de influir de un anuncio publicitario en particular 
alimentarios no sanos. Pero no serviría de nada discutir sobre ello, puesto que hoy por hoy es mera retórica el preguntarse cómo podría va una cadena de televisión (o cualquier otra organización) capar su principal fuente de ingresos, y dar la cara frente a sus accionistas y proveedores.

\subsection{Anuncio de Puntomatic}

Este anuncio, que acaba de producirse y está en medios actualmente, se vincula, según declara el fabricante, dentro de una campaña social que persigue la igualdad de género en el reparto de las tareas domésticas. "Persan ha decidido no hablar de Puntomatic en la última estrategia de este detergente. En su lugar lo ha convertido en artífice de la campaña Un mundo sin manchas para promover el reparto igualitario del trabajo en el hogar y, así, luchar contra las manchas que no están en la ropa, sino en la sociedad.”11. Esta campaña consta de un spot televisivo, y de un plan de relaciones públicas ("road show" de un autobús visitando nuestras ciudades, "Curso instantáneo para poner la lavadora”, y entrega de lavadoras a líderes de opinión, según declara Persan).

Se vende esta campaña con la afirmación de que no se habla del producto (en publicidad no es vital hablar del producto, simplemen-

\footnotetext{
${ }^{11}$ Brandlife: "Puntomatic lanza una 'campaña social' para la igualdad en las tareas domésticas". Enlace eletrónico en

[http://www.brandlife.es/noticia.asp?ref=302] consultado el 28 de noviembre de 2007.
}

te con firmar el anuncio se cumple la función de esta herramienta de comunicación comercial) y así la finalidad de la acción es la educación social. Como se ha argumentado en ejemplos anteriores, esto simplemente responde a una política comunicativa de imagen, y en realidad esta campaña es simple y llanamente comercial. Lo es así por que primeramente aparece la marca, y por lo tanto busca beneficios en la órbita de la imagen. En segundo lugar, presumiblemente se ha marcado un público objetivo (los hombres) con la excusa de educarles, pero lo que hay realmente es la intención de vender detergente a un público específico, al que nunca antes se habían dirigido este tipo de campañas. El estereotipo de hombre que presenta la campaña no es realmente el público objetivo, ya que este
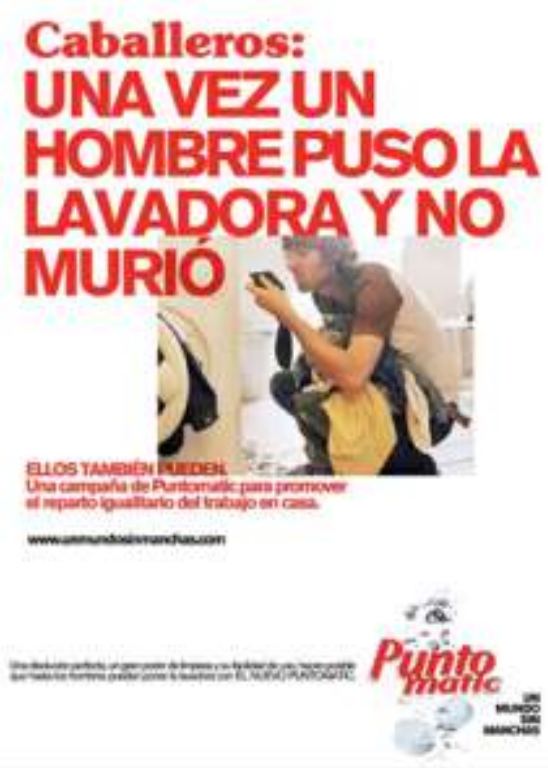

Fig. 9 Campaña de Puntomatic 
tipo de personas directamente no van a poner una lavadora. El target real son aquellas personas, sobre todo varones, que viven solos, que son jóvenes, y que en realidad sí utilizan ya la lavadora, es decir, un público factible. De este modo se utiliza el argumento del machismo como un recurso creativo para darle notoriedad e incluso un pretendido toque de humor a la campaña . En conclusión, esta iniciativa, comparada con las otras es en realidad más de lo mismo.

\subsection{Campaña "energía ver- de" de Iberdrola}

Esta campaña se vincula al Plan Estratégico 2002-2006 de la compañía eléctrica como una apuesta firme a favor del medio am-

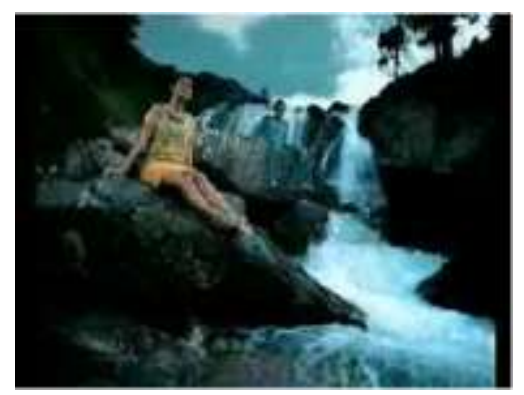

Fig. 10 Fotograma campaña Energía Verde de Iberdrola

biente. Antes de nada, es conveniente transcribir el texto de esta pieza, ya que es muy breve y elocuente: "Hoy miles de personas ya se han cambiado a la Energía Verde Iberdrola, ya cuidan del medio ambiente. ¿y tú? ¿A qué esperas? Cuantos más seamos, más cuidaremos de nuestro planeta. Cámbiate a la Energía Verde Iberdrola.
9012020 20”. Tras este mensaje publicitario, Iberdrola argumenta que "Por primera vez en España hogares, empresas, organismos y entidades públicas podrán contratar electricidad procedente de fuentes de energía 100\% renovables, y libre de emisiones de gases que provocan el efecto invernadero" "12, y así se pone de manifiesto el compromiso de la empresa con el medio ambiente.

La cuestión desgraciadamente se nos complica cuando intentamos saber qué se esconde en realidad, y descubrimos que esta campaña ha sido muy controvertida e incluso el caso en cuestión ha llegado a los tribunales. Hacemos un breve repaso: En 2003 la Comisión Nacional de la Energía (CNE) abrió un expediente informativo a Iberdrola

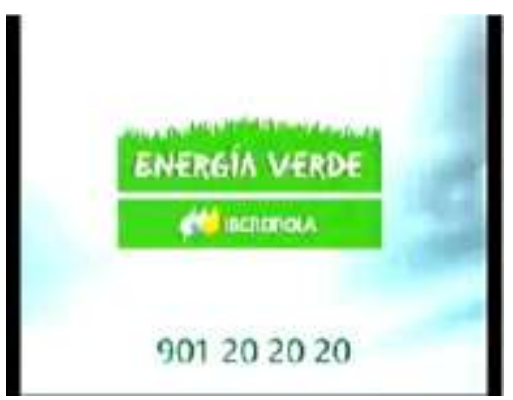

Fig. 8 Campaña 12 meses, 12 causas

12 Esto debe ser casi literal del comunicado o rueda de prensa que hizo la compañía para lanzar esta campaña, ya que coincide en todos los medios consultados. La cita está tomada literalmente del portal de información de terra en el enlace

[http://www.terra.es/actualidad/articulo/html/act58978.ht m] consultado el 29 de noviembre 2007. 
y Endesa por la venta de Energía Verde ${ }^{13}$. Dicho expediente se fundamentó en dos argumentaciones principales. La primera ponía en evidencia que los clientes finales ya pagan un sobrecoste en la factura de la luz para contribuir con el desarrollo de las energías renovables. El segundo juicio se basaba en que la energía que producen las compañías eléctricas sean limpias (verdes) o sucias $^{14}$, toda se almacena en el mismo lugar, y luego es distribuida, por lo que el cliente final lo que compra simplemente es energía, y no energía verde o marrón. Este informe provocó que numerosas organizaciones tomasen algún tipo de iniciativas y llevasen el caso a los tribunales ${ }^{15}$.

La asociación Ausbanc ${ }^{16}$ movilizó sus servicios jurídicos en octubre de 2004, y en marzo de 2005, contra todo pronóstico, el Juzgado de primera instancia número 15 de Madrid desestimó la petición de medidas cautelares que se solicitaba contra Iberdrola, a pesar de que el informe de la CNE, acusaba claramente de engaño a la compañ-

${ }^{13}$ Publicado por Santiago Carcar en El País. Enlace electrónico disponible en [http://www.rebelion.org/ecologia/031029cne.htm] consultada el 29 de noviembre 2008

${ }^{14}$ Son las que producen $\mathrm{CO} 2$ en su fabricación.

${ }^{15}$ En la revista mensual FUSIÓN encontramos artículo dedicado a este caso, y lo podemos consultar en línea en el enlace

[http://www.revistafusion.com/2004/octubre/report133.ht m] consultado el 11 de noviembre de 2007.

16 Greenpeace también mantuvo una postura muy enfrentada a esta campaña.
$1 a^{17}$. No sabemos si ha prevalecido el poder de las eléctricas o la justicia ciega. La cuestión que a nosotros nos interesa, en este texto de manera específica, se centra en el uso de un mensaje publicitario que en realidad simplemente es un reclamo comercial, al igual que en los otros casos analizados, y que por lo tanto no contribuye ni de lejos a mejorar la sostenibilidad del medio ambiente, sino de lucrar a las empresas que los ponen en marcha, y tranquilizar a las inocentes conciencias de los clientes de buena fe. Si profundizamos en el tema, estas son las deducciones a las que llegamos. Una vez más, este tipo de mensajes, en realidad son comerciales en su esencia, y no persiguen el cambio social, a pesar de su discurso superficialmente comprometido.

\footnotetext{
${ }^{17}$ Portal de documentos jurídicos luxor. Texto disponible en el enlace

[http://www.lexureditorial.com/noticias/0503/28143040.h tm] consultado el 24 de noviembre de 2008.
} 


\section{Conclusiones}

Atendiendo al discurso de muchas campañas publicitarias, y de iniciativas de RSC, asumimos que la comunicación de causas está de moda. Las empresas han descubierto una nueva forma de vender y venderse, con un discurso amable y comprometido, cuya finalidad es la misma que la de las técnicas más agresivas de marketing que buscan cerrar la venta. Con este tipo de mensajes, las empresas transmiten de sí una imagen de responsabilidad social, comprometida y flamante que puede hacer que el consumidor sienta también un alivio de conciencia comprando o depositando su confianza en una empresa comercial que se hace garante de los derechos y mejoras, tanto civiles como mediambientales. Ocurre que la sociedad evoluciona, cambia, y por lo tanto los discursos sociales se van adaptando a las nuevas circunstancias de mercado y cultura social. Debemos por tanto ser capaces de diferenciar bien, a pesar de sus similitudes formales, las campañas sociales y de las comerciales con apariencia social, como se ha venido discutiendo en este texto. En este sentido, aquí se ha argumentado qué es la publicidad social conceptualmente, y se ha demostrado que muchas de las campañas sociales más famosas, deben clasificarse realmente como comerciales, y de este modo el adjetivo 'social' se vincularía al género en lugar de al tipo (del mismo modo que tenemos publicidad comercial de aceite de oliva, cuyo género publicitario puede ser musical, solución de problemas o escenas de vida).

Inducir cambios sociales, desde los argumentos defendidos en este artículo, es una posibilidad a tener en cuenta para fomentar el cambio social que haga de nuestro planeta un mundo más habitable (ecológicamente hablando), más justo y solidario (socialmente hablando). En realidad esta tarea es responsabilidad de todos y cada uno de los actores sociales, pero sobre todo están llamados a ser la vanguardia de un compromiso férreo con esta tarea de educación social, las Administraciones y los distintos colectivos sociales. Lo ideal sería llevar hacia delante esta tarea de forma coordinada para hacer efectivo un plan global para el fomento de la educación social, que en realidad es trabajar, en sentido amplio, para la cultura de paz (Cortés, 2007) (Fisas, 1998), (Galtung, 1996) ${ }^{18}$.

\footnotetext{
${ }^{18}$ La cultura de paz recoge y desarrolla todos los principios por los que trabaja la llamada publicidad social, según la hemos abordado en este artículo.
} 
Defendemos el uso de la publicidad para este quehacer porque siempre que compremos los espacios y tiempos en los medios, podremos decir lo que queramos en los mismos, y se encontrará el emisor (anunciante) más libre a la hora de expresar lo que estime oportuno, sin la presión de una línea editorial concreta. Esto no quiere decir que se desprecien otras formas importantísimas de comunicación estratégica como pueden ser las Relaciones Públicas o la comunicación de guerrilla, sino que son casi obligatorias en un plan serio de este tipo, y es fundamental emplear formas comunicativas no convencionales. Pero aquí estamos hablando de publicidad, que aunque muchos ya le den por muerta, sigue teniendo su espacio y sus efectos ${ }^{19}$.

Queremos reiterar una vez más, la recomendación de poner en marcha un plan coordinado, no solo de publicidad sino de comunicación, para el fomento de la cultura de paz (referente de la publicidad llamada social) a través de los medios de comunicación social, satisfaciendo así la vocación de cambio que defienden formalmente los estados y gran número de colectivos sociales. Y por supuesto, exigimos que si las empresas nos quieren vender sus productos con estos mensajes (están en su legítimo

\footnotetext{
${ }^{19}$ En el año 2008, Infoadex publicó que el presupuesto publicitario en España destinado a medios convencionales superó los 14.000 millones de euros. Es decir, la publicidad convencional aún ostenta una fortaleza indiscutible.
}

derecho), que lo hagan pero sin dar de lado al compromiso real. De lo contrario, lo diga la justicia o no, se estará incurriendo en engaños y tomaduras de pelo, tratando a la población (consumidores) como una masa sin criterio que se moviliza a golpe de tendencias sociales. 


\section{Referencias}

ÁLVAREZ RUIZ, A. (2003). La función social de la publicidad de la ONCE. Madrid: Escuela Libre Editorial y Fundación ONCE.

\section{ASOCIACIÓN ESPAÑOLA DE AGENCIAS DE} PUBLICIDAD (1991). La publicidad en la administración española. Madrid: AEAP.

ALVARADO LÓPEZ, M.C. (2003). La publicidad social: una modalidad emergente de comunicación (tesis doctoral). Madrid: Universidad Complutense de Madrid.

BARRANCO, F.J. (2003). Marketing político. Madrid: ESIC.

CHAMIZO SÁNCHEZ, R. (2006): "Los asuntos sociales en los medios de comunicación. De la publicidad social y sus técnicas disuasorias". En MÍNGUEZ, N. y VILLAGRA, N. (eds.): La comunicación, nuevos discursos y perspectivas. Madrid: Edipo.

CORTÉS GONZÁLEZ, A. (2007). Cultura de paz y publicidad institucional. El Estado en el fomento de la cultura de paz a través de la publicidad televisiva. Jaén: Alcalá Grupo Editorial.

DOBSON, A. (1997). Pensamiento Político Verde. Una Nueva Ideología Para El Siglo XXI. Madrid: Paidós.

FELIU, E (2004). La Publicidad Social. En AA.VV: La comunicación: nuevos discursos y perspectivas. Madrid: Edipo.

FERNÁNDEZ SÁNCHEZ, J. (1999). El ecologismo español. Madrid: Alianza Editorial.
FISAS, V. (1998). Cultura de paz y gestión de conflictos. Barcelona: Icaria

GALTUNG, J. (1996). Peace by peaceful means. Londres: SAGE.

GARCÍA LÓPEZ, M. (2001). Publicidad Institucional: El Estado Anunciante. Málaga: Servicio de Publicaciones Universidad de Málaga.

KAPLÚN, M. (1998). Una pedagogía de la comunicación. Madrid: La Torre.

KOTLER, P. y ROBERTO, E.L. (1998). Marketing social. Estrategias para cambiar la conducta pública. Madrid: Díaz de Santos.

LEAL JIMÉNEZ, A.(2000). Gestión del Marketing Social. Madrid: McGRaw Hill.

MARTÍNEZ ALIER, J. (2005). El ecologismo de los pobres. Barcelona: Icaria.

MC LUHAN, M. (2001). Understanding media: the extensións of man. Londres: Routledge.

MOLINER, M.A. (1998). Marketing social: la gestión de las causas sociales. Madrid, ESIC.

PÉREZ TORNERO, J.M. (1994). El desafío educativo de la televisión. Barcelona: Paidós.

QUALTER, T.H. (1994). Publicidad y democracia en la sociedad de masas. Barcelona: Paidós.

VIEDMA GARCÍA, M. (coord.)(2003). Manual de Publicidad Administrativa no sexista. Málaga: Asociación de Estudios Históricos sobre la Mujer, Universidad de Málaga, Área de la Mujer del Ayto. de Málaga. 
VÁZQUEZ MEDEL, M.A. (1999). Mujer, Ecología Y Comunicación En El Nuevo Horizonte Planetario. Sevilla: Mergablum. Edición y Comunicación, S. L.
VV.AA.(2000). Comunicación pública: la información administrativa al ciudadano. Madrid, Marcial Pons

Cita de este artículo

Alfonso Cortés González y José Patricio Pérez Rufí: Ecologismo, Igualdad y Responsabilidad Civil. Revista Icono14 [en línea] 1 de noviembre de 2009, № 13. pp. 75-94. Recuperado (Fecha de acceso), de http://www.icono14.net 